Res Pública Revista de Historia de las Ideas Políticas

ISSN: $1131-558 \mathrm{X}$

http://dx.doi.org/10.5209/rpub.71088

\title{
El acontecimiento de la inversión dialéctica
}

Berta M. Pérez ${ }^{1}$

Recibido: 11 de agosto de 2020 / Aceptado: 25 de septiembre de 2020

Resumen. Este ensayo trata de explicar en qué sentido la interpretación que hace Žižek de la inversión dialéctica de Hegel la ilumina como acontecimiento. En la medida en que en ella sustancia y sujeto sólo coinciden con su otro en su más interno desajuste, se pone al descubierto que ambos se preceden mutuamente: que la sustancia ya siempre se mira a través del sujeto, pero que, a la vez, la mirada del sujeto está siempre limitada por un punto ciego que testimonia la precedencia de la sustancia. Es por esto por lo que en el (des-)encuentro dialéctico de los opuestos el "antes" y el "después" del tiempo se va a pique y, así, lo nuevo puede emerger verdaderamente. Finalmente, el trabajo clarifica la especificidad de la subversión que lleva a cabo el punto de vista dialéctico: al retrotraer a la negación auto-relacionada de la inversión dialéctica la identidad de cualquier posición, ésta resulta desenmascarada en su carácter ideológico a la vez que comprendida desde el necesario encubrirse de la negación. Se explica entonces que, lejos de pretender situarse en un terrero exterior al antagonismo y la ideología, este pensamiento se sepa siempre como parte comprometida.

Palabras clave: Žižek; Hegel; negación auto-relacionada; acontecimiento; ideología.

\section{[en] The Event of Dialectical Inversion}

Abstract. This essay tries to show in which sense Žižek's interpretation of the Hegelian dialectical inversion illuminates it as an event. To the extent that, in inversion, substance and subject only coincide with each other in their internal mismatch, it turns out that both precede each other: that the substance is always seen beforehand through the subject, but that, equally, the subject's gaze is always limited by a blind spot that betrays the precedence of substance. For this reason, in the dialectical (dis-)encounter of opposites, the "before" and "after" of time collapses and, thus, the new can truly emerge. Finally, I explain the specificity of the subversion undertaken by the dialectical point of view: by referring the identity of any position to the self-reflective negativity of the dialectical inversion, it unmasks this identity in its ideological character and, at the same time, comprehends it as the unavoidable disguise of negation. Accordingly, it becomes apparent that dialectical thought, far from pretending to dwell on a terrain beyond antagonism and ideology, is aware of being always a committed party.

Keywords: Žižek; Hegel; Self-related negation; Event; Ideology.

Sumario. 1. El elemento y el método. 2. El descubrimiento de la negatividad. 3. La negatividad abstracta o la destructividad del acontecimiento. 4. La negación auto-relacionada o la simbolización del acontecimiento. 5. El tiempo no es. 6. La dialéctica como crítica de la ideología. Bibliografía.

Cómo citar: Pérez, B. M. (2020). El acontecimiento de la inversión dialéctica. Res Pública. Revista de Historia de las Ideas Políticas, 23(3), 355-366.

La metafísica de Žižek es la hegeliana. El problema abierto por Kant con el "descubrimiento trascendental" es para Žižek, todavía hoy, el problema de la filosofía contemporánea y la metafísica con la que Hegel lo enfrentó sigue siendo para él la respuesta que se debe dar al mismo ${ }^{2}$. El programa de esta metafísica lo expresa Hegel diciendo que el pensamiento filosófico ha de "aprehender y expresar lo verdadero no como sustancia, sino, en la misma medida, como sujeto"'s. Y la realización de este programa consistió para él en conformar la filosofía como movimiento dialéctico. Pensar la sustancia como sujeto es pensar dialécticamente. Consiguientemente, la metafísica de Žižek toma el movimiento dialéctico por la verdad de la realidad.

Ahora bien, la filosofía de Žižek es conocida asimismo como una metafísica de lo Real lacaniano, es decir, como un pensamiento que defiende el carácter no-todo de la realidad partiendo, al igual que el último Lacan, de que es la imposible "coincidencia de los opuestos" lo que constituye lo Real, esto es, el núcleo más verdadero de la realidad. Se entiende entonces que, dada la comprensión habitual, poco menos que "natural", de la

\footnotetext{
berta.m.perez@uv.es

Universidad de Valencia

2 La cuestión de cómo puede responder la filosofía contemporánea al reto planteado por el trascendentalismo kantiano, de si puede o no superar el enfoque trascendental, se puede considerar, en efecto, el hilo conductor de S. Žižek, Contragolpe absoluto. Para una refundación del materialismo dialéctico, trad. A. J. Antón, Madrid, Akal, 2016; cf. pp. 11, 23, 103.

3 G. W. F. Hegel, Fenomenología del Espíritu, trad. A. Gómez Ramos, Madrid, Abada, 2010, pp. 71-73.
} 
dialéctica como el movimiento teleológico que, suprimiendo los antagonismos de la realidad, la comprende como una totalidad completa y consistente, el hegelianismo de Žižek produzca cuando menos desconcierto. Por su inaudito cruce entre Hegel y Lacan, su lectura de la filosofía hegeliana es despachada en ocasiones como el resultado de la pura "proyección" de cierto Lacan sobre Hegel.

En contra de esta recepción, en lo que sigue trataré de mos 2. El descubrimiento de la negatividad trar cómo la interpretación que hace Žižek de la inversión dialéctica logra traer a la luz el absoluto hegeliano como el puro desajuste entre la sustancia y el sujeto que, como acabo de recordar, el programa de Hegel se propuso mediar. La lectura de Žižek revela ese desajuste como el auténtico absoluto y muestra además que el carácter específico y único de la relación entre los opuestos que de ello se deriva implica una comprensión del tiempo que lo rompe desde dentro al tomarlo como pura contradicción. Por eso su interpretación de Hegel se deja leer como el gesto que ilumina la inversión dialéctica, contra la lectura tradicional, como un acontecimiento. Esta operación es en definitiva lo que intentaré analizar en estas páginas. Además, argumentaré que el descubrimiento de la relación hegeliana de los opuestos y de su tiempo en estos términos justifica que Hegel, más incluso que Schelling, sea el "autor de cabecera" de Žižek. Al iluminar estos conceptos no sólo se comprende el sentido en el que la negatividad hegeliana converge con la pulsión de muerte lacaniana, sino también, y en especial, el potencial subversivo que encierra en sí mismo el pensamiento dialéctico.

\section{El elemento y el método}

Para exponer la interpretación žižekiana de la inversión dialéctica partiremos de su lectura de un pasaje de la "Lógica de la esencia" de la Ciencia de la lógica de Hegel, concretamente de su primera sección, la que se dedica a la reflexión de la esencia o a la esencia como reflexión. Se trata de un lugar especialmente adecuado para comprender la dialéctica en términos de sustancia y sujeto. No por casualidad Žižek se ha detenido a comentarlo en varias de sus obras. No obstante, antes de abordar esta interpretación, conviene hacer algunas aclaraciones sobre el proceder dialéctico en la Ciencia de la lógica.

La esencia, el objeto de la segunda parte de esta obra, es a la vez una determinación de las cosas, o del ser, y del pensamiento, o del sujeto -si se prefiere, del lenguaje-. Como es sabido, esto vale para todas las determinaciones de las que se ocupa la obra, en la medida en que su punto de partida es la sustancia-sujeto o el absoluto mismo, es decir, en la medida en que la Fenomenología del Espíritu ya ha hecho el camino, como se dice habitualmente, desde el punto de vista de la conciencia (finita) al del espíritu (absoluto). Pero importa señalar ya -aunque sólo más adelante se explique cabalmente-que el elemento así ganado, el del sistema filosófico y en especial el de la Lógica, es, en palabras de Žižek, la inma- nencia misma, es decir, el espacio de la finitud ${ }^{4}$. Importa tener ya presente que movernos en la dimensión de lo absoluto hegeliano significa para Žižek permanecer estrictamente dentro del ámbito finito de nuestra realidad y de nuestro pensamiento, liberados realmente del fantasma y la carga de cualquier trascendencia. Significa permanecer en la esfera de la experiencia (finita) después de que la Fenomenología -el lugar donde Hegel se convierte en Hegel midiéndose con Kant, trascendiéndolo en su propio terreno y en sus propios términos- haya liquidado la cosa-en-sí que aquél, a pesar de haber operado el giro trascendental, todavía se permitía reconocer. Žižek no se cansa, en efecto, de insistir en que lo que el desplazamiento de Hegel en Jena, especialmente explícito en la Fenomenología, nos proporciona no es el acceso (vedado por Kant) al más allá del fenómeno, sino, muy al contrario, el saber de que no hay tal más allá .

En relación a la Fenomenología Žižek toma en ocasiones las distintas figuras de la conciencia, en tanto que constituyen el lado del saber (finito) de ese sujeto finito, como el momento del sujeto, y hace corresponder lo en-sí o la verdad que presupone cada uno de estos saberes con el momento de la sustancia, de modo que el trayecto que recorre el texto aparece como el que retrotrae la sustancia, entendida como cosa-en-sí, al sujeto ${ }^{6}$. Sus comentarios de distintos lugares de la Ciencia de la lógica, sin embargo, asocian a menudo la sustancia a las determinaciones que componen su índice, tomando así "sustancia" en el sentido ya propiamente hegeliano, como sustancia ya siempre espiritual o como cosa-concepto. El gesto que hace la obra aparece entonces como el de dejar que dichas determinaciones sustantivas, al ser observadas en su propio realizarse, sin trascender su inmanencia, tropiecen con el sujeto como con su propio desgarro. En ambos casos, pues, aunque se haya tomado "sustancia" en sentidos distintos, transitamos desde ésta hasta el sujeto7 ${ }^{7}$. Esto puede inducir a pensar que Žižek reconoce la finitud hegeliana únicamente en el lado del

\footnotetext{
Žižek emplea el término "inmanencia” en este sentido en The Parallax View, Cambridge (Mass.)/London, The MIT Press, 2009, pp. 36 ss.

Hegel es para Žižek el Hegel que nace de Kant, el que en la época de Jena responde adecuadamente al giro trascendental. En todas las obras en las que Žižek se ocupa de Hegel presenta su filosofía en estos términos. Pienso, por lo demás, que su interpretación -no sólo su idea de que el pensamiento de Hegel se conforma en el diálogo con Kant en este periodo, sino también la de que consiste en vincular los opuestos a través de la consumación de la liquidación de toda trascendencia- encuentra respaldo no sólo en la Fenomenología, sino también en muchos pasajes de otros escritos de Hegel de su etapa de Jena, como el Escrito sobre la diferencia y, en especial, Fe y saber, pero no puedo detenerme aquí a mostrarlo.

6 La contraposición de saber/concepto/para-sí y verdad/objeto/en-sí como clave para la lectura de la obra la proporciona el propio Hegel, como es bien sabido, en la Introducción: Fenomenología del Espiritu, op. cit., p. 155. En Porque no saben lo que hacen Žižek explica el tránsito de Kant a Hegel a propósito de la dialéctica de estos momentos y la traduce ya a los términos de forma y contenido; cf. Porque no saben lo que hacen. El goce como un factor politico, trad. J. Piatigorsky, Buenos Aires, Paidós, 2006, pp. 215-218.

En Porque no saben lo que hacen el movimiento dialéctico se presenta efectivamente en primera instancia como un movimiento que conduce de la sustancia al sujeto y que, de este modo, la muestra como no-toda; cf. el capítulo "Lalengua hegeliana", en Porque no saben lo que hacen, op. cit., pp. 137-188, esp. pp. 137-140 y 146147.
} 
sujeto (en tanto que meta del camino), pero en realidad las correspondencias se pueden hacer en el sentido inverso; podemos partir de las determinaciones como del momento subjetivo, como del plano del pensamiento o el lenguaje, para llegar, haciendo el mismo trayecto, a la sustancia no-toda que (no) lo sostiene. La finitud de Hegel no se corresponde, pues, con uno sólo de los lados de la sustancia-sujeto, sino con ella misma, con lo absoluto como tal.

El elemento de la dialéctica o de la Ciencia de la lógica, siendo lo absoluto, no es para Žižek nada distinto, pues, de nuestra realidad (en su ser conceptual o lingüístico). Sólo así puede la posición de Hegel ser lo que Žižek dice que es, a saber: el único modo de no llevar a Kant hacia ningún sitio que no sea su propia coherencia, la única forma posible de liberarlo del fantasma de su miedo sin trascender nuestra finitud hacia algún principio previo o en-sí, es decir, siendo fiel al propio giro trascendental. Es esto lo que, a mi parecer, sitúa a Hegel, para Žižek, por encima incluso de Schelling, por encima, de hecho, de cualquier autor contemporáneo, salvo de Lacan ${ }^{8}$.

Así que la forma hegeliana de concebir la relación entre sustancia y sujeto y, por ende, lo absoluto de su vínculo, habrá de mostrársenos sin que nos apartemos un ápice de nuestra realidad. Se nos dará a ver en la misma medida en que aprehendamos esta realidad dialécticamente, en el núcleo mismo de su inversión dialéctica. Éste es el trabajo que hace Žižek en sus comentarios de los textos hegelianos, y lo que él considera que hace el propio Hegel a través de una estrategia - o, si se quiere, método- que es común a la Fenomenología y a la Ciencia de la lógica y que no consiste sino en mirar cada figura o cada determinación absteniéndose de proyectar una perspectiva externa, es decir, dejando que lo mirado se afirme o se "ponga en escena" por sí mismo". Aprehenderlo en este su "drama" es tomarlo en el movimiento de su realización finita o en la actividad de su exteriorizarse, en lo que consiste, desde la óptica hegeliana, su verdad. Es en este drama, en efecto, donde se cruzan y tropiezan sustancia y sujeto, de modo que, finalmente, como veremos, es él mismo, en tanto que expresión del desajuste de los dos lados, lo único absoluto. Frente a este mirar, la perspectiva que, por el contrario, mira desde fuera, desde más allá de la cosa, es la que la proyecta hacia una identidad interior que la fija, hacia un fantasma que "positiviza" el miedo (o la ternura) que nos ha llevado a adoptar ese punto de vista trascendente (o trascendental). Es esta perspectiva, pues, y no la dialéctica, la que se revela cómplice de un absoluto en-sí o, como diría Hegel, subsistente de suyo ${ }^{10}$.

Hegel da en este sentido un paso más allá no sólo del Schelling “spinoziano", donde la indeterminación entre los opuestos aparece como un tercero o principio externo, sino también respecto del Schelling posterior, del Escrito sobre la libertad y Las edades del mundo, que, aun siendo crucial para Žižek, al hablar en términos "míticos" reconoce en todo caso una brecha de la sustancia que es previa al sujeto, el lenguaje y la historia. Cf. El resto indivisible, trad. A. Bello, Buenos Aires, 2013, esp. pp. 169-175 y 205-223.

9 En relación a este "método" y al modo en que para Žižek acerca al segundo Wittgenstein a la dialéctica hegeliana, cf. Porque no saben lo que hacen, op. cit., pp. 190-195 ("El teatro histérico de Hegel").

10 Es el reine Zusehen de la Fenomenología lo que finalmente explica Žižek cuando expone la estrategia hegeliana como el "dramatizar".

\section{El descubrimiento de la negatividad}

En Contragolpe absoluto Žižek explica la inversión dialéctica a partir de un pasaje de la Ciencia de la lógica donde se condensan los momentos principales de la reflexión de la esencia en cuatro pasos. Los reconstruye así: (1) un desorden inconsistente que es negado; (2) la postulación "hacia atrás", desde esta negación, del desorden como origen; (3) la relación con ese origen como con una presuposición trascendente o la reflexión externa; y (4) la transposición de este movimiento reflexivo al origen mismo como su auto-retirada o la reflexión absoluta ${ }^{11}$. Los momentos (1) y (2) se podrían hacer corresponder con la reflexión ponente de la que parte Hegel en el capítulo en cuestión, pero el interés de Žižek está en el tránsito entre (3) y (4), en el contragolpe (Gegenstoss) que ahí tiene lugar. Y, en verdad, (1) y (2) están ya contenidos en (3). Esta reconstrucción será, pues, nuestro hilo conductor.

La posición de un origen que señalan los dos primeros momentos es el punto de partida de la reflexión externa en el sentido de que ella comienza por tomar una posición determinada o una determinación - un concepto y/o un objeto, según lo ya explicado- como algo positivo que tiene enfrente, esto es, por presuponerlo como siendo en-sí. Esa posición o tesis de partida se deja leer entonces como momento sustancial, donde sustancia significa efectivamente aquello que tiene su ser en sí mismo, que es en-sí. Pero se puede tomar a la vez como la posición de la identidad de un objeto y como la posición de la universalidad de un género o incluso como la posición del sujeto de un juicio (en la medida en que la posición de un género es siempre la afirmación de un juicio). En todo caso la reflexión externa presupone esa tesis como su origen trascendente y, en este sentido, encarna el punto de vista de la dualidad o, como dice Hegel, de la exterioridad. Al constituirse en esta relación con un origen presupuesto, se coloca a sí misma, efectivamente, más allá de él, lo mira desde fuera como a su otro, y se autocomprende en definitiva como el momento de la negación o de la antítesis: ella es el punto de vista que contrapone la diferencia a la identidad, la especie particular al género universal, el predicado al sujeto

El punto de vista trascendental como punto de vista externo es criticado por Hegel en la Introducción (Fenomenología del Espíritu, op. cit., p. 157). La ternura de Kant por o hacia las cosas, que expresa la resistencia a reconocer la contradicción como su verdad o el miedo a que pierdan su "identidad", es diagnosticada por Hegel en la Enciclopedia de las ciencias filosóficas en compendio, trad. R. Valls, Madrid, Alianza, 1997, § 48, Observación. Žižek entiende que Hegel detecta el apego de Kant a la ilusión de una verdad más allá de ese fenómeno, de un en-sí libre de toda contradicción, así como su consecuente complicidad con la trascendencia de la metafísica que, por otro lado, su propio giro liquida. Cf., por ejemplo, S. Žižek, Menos que nada. Hegel y la sombra del materialismo dialéctico, trad. A. J. Antón, Madrid, Akal, 2015, pp. 297 y 308 ss.

11 Cf. Contragolpe absoluto, op. cit., pp. 157 ss. El pasaje de la Lógica se encuentra en Ciencia de la lógica. I. La lógica objetiva, trad. F. Duque, Madrid, Abada, 2011, pp. 447-456 (esp. p. 450). Žižek comenta también la lógica de la reflexión (o de la posición y la presuposición) en varias de sus otras obras: por ejemplo, El sublime objeto de la ideología, trad. I. Vericat, México, Siglo XXI, 1992, pp. 271 ss. y Tarrying with the Negative. Kant, Hegel, and the Critique of Ideology, Durham, Duke University Press, 1993, pp. 125-130. 
$\mathrm{y}$, en última instancia, el para-sí del sujeto o la reflexión al en-sí de la sustancia ${ }^{12}$.

El primer tiempo del contragolpe que constituye la inversión dialéctica tiene lugar, sin embargo, solamente en la medida en que esta reflexión descubre su presupuesto como puesto (por ella misma), es decir, cuando descubre que su origen sólo es tal por su relación con ella, es decir, por su propio presuponerlo como origen. Sabe entonces que la verdad de lo en-sí es el para-sí y la de la tesis, la antítesis, que la especie es antes que el género, la diferencia antes que la identidad o el predicado del juicio antes que su sujeto. Este desmantelamiento del momento sustancial (en tanto que contrapuesto al movimiento reflexivo) es para Žižek efectivamente un rendimiento crucial y definitivo de la dialéctica hegelia$\mathrm{na}^{13}$. Por eso se detiene en tantas ocasiones a recordarnos distintos ejemplos que Hegel proporciona: nos da a ver que (la negatividad de) el robo es previo a la propiedad (como ley universal), que la especie de la transgresión pura (junto a otras transgresiones determinadas) es previa al género del deber kantiano, que el sujeto en el juicio aristotélico viene del reflejarse del predicado o que la sustancia ética como fundamento en-sí es sólo puesta por el obrar de Antígona ${ }^{14}$.

Ciertamente, no es Žižek el único en reconocerle este logro a la dialéctica hegeliana: incluso críticos tan severos como Adorno le conceden el mérito de haber echado por tierra el mito de la inmediatez, es decir, el supuesto de una realidad en-sí, absolutamente al margen de nuestro pensarla, decirla y transformarla ${ }^{15}$. Pero es Žižek quien muestra la radicalidad de este momento al subrayar cómo en esta misma caída de la sustancia o de la tesis cae también el sujeto o la antítesis. El descubrir el origen como siendo sólo puesto, como no teniendo su ser en sí, sino en la propia reflexión, el descubrir que el origen sustancial tiene su origen en la negatividad reflexiva o subjetiva, podría inducirnos a pensar -como lo prueban, en efecto, numerosas interpretaciones- que Hegel ha sustituido un principio por otro y que nos ofrece así la reflexión o la mediación del sujeto como el nuevo principio. Pues bien, frente a esta lectura, la de Žižek insiste en que el saber del carácter puesto del origen "positivo" es también el saber de la dependencia de la propia reflexión -el otro del origen- respecto a

12 Cabe recordar que, como señala el propio Žižek más de una vez, los términos "tesis" y "antítesis" (así como "síntesis") no son propiamente hegelianos. Se emplean aquí, pues, no para atribuir a $\mathrm{He}$ gel el rígido esquema que, tradicionalmente, se le ha impuesto, sino únicamente, por su significado etimológico, para hacer referencia a una posición en general ("tesis") y a la negación de la misma ("antítesis").

13 Supone, en efecto, para empezar, que la reconciliación de Hegel no podrá significar en ningún caso la recuperación de esta sustancia (subsistente de suyo), y esto le proporciona a Žižek la primera razón para rechazar las lecturas habituales de Hegel, en la medida en que acaban por convertir su absoluto en una identidad primera, originaria. Para el rechazo žižekiano del movimiento dialéctico como movimiento de reapropiación así como de su comienzo a partir de una posición positiva, cf. Contragolpe absoluto, op. cit., pp. 163 y 203.

14 Para esta prioridad de la negación respecto a toda posición, cf. $\mathrm{Me}$ nos que nada, op. cit., pp. 329-332.

15 Cf. Th. W. Adorno, "La sustancia experiencial", en Tres estudios sobre Hegel, trad. V. Sánchez de Zavala, Madrid, Taurus, 1974, pp. 77-118. él. Por eso Antígona se desmorona cuando la sustancia ética se desmorona, el robo no se entiende si no es por referencia a la propiedad, ni la transgresión al margen de la ley. Pero, sobre todo, Žižek aclara que esto es así no en virtud de una relación (externa) entre el contenido de la tesis y el de la antítesis, sino porque la posición original que se viene abajo en el comienzo de este golpe no es nada más que el resultado del ponerse de la reflexión misma, del afirmarse de la negatividad reflexiva (o parasí) como algo que en verdad "es" (positivamente o ensí). Si se lee con cuidado a Hegel se descubre entonces que el desmantelamiento del en-sí sustancial es también el del sujeto (como principio), por la razón "estructural" de que el primero no sólo nace del segundo, sino que es el segundo en el mismo instante en el que éste se pone o se afirma, en el que se da una universalidad y una identidad. Por eso lo importante para comprender la radicalidad de este tránsito no es ver que la ley es posterior a la transgresión o el género a la especie, sino descubrir que la transgresión, para afirmar su identidad, ha de negarse y ocultarse en la forma de la ley o que el género es en verdad la especie que, para universalizarse, se cambia en su contrario, es decir, se autoexcluye o se reprime (como especie) ${ }^{16}$. Por esto destaca Žižek a menudo que Hegel reconoce que el género se contiene a sí mismo como especie, y explica que es esta especie, sólo en tanto que negada, la que lo sostiene ${ }^{17}$. Y también por esto define el sujeto (hegeliano) como un movimiento de universalización ilegítima, como el resultado de una acción totalitaria ${ }^{18}$. Toda sustancia, todo origen presupuesto como en-sí es una expresión de la autoafirmación totalitaria, de la hybris, de la negatividad reflexiva que se quiere como sub-jectum.

Lo que se ha venido abajo ya en el momento de la reflexión externa es, en definitiva, el fundamento ( $s u b$ jectum) o el principio en general, es decir, la identidad y la universalidad -sea de la sustancia, sea del sujeto-, pero también la diferencia exterior de las contraposiciones propias de esta reflexión -por ende, la exterioridad de la contraposición misma entre sustancia y sujeto ${ }^{19}$-. Esto explica que, en la lógica hegeliana de las "esencialidades", lo que sigue a la oposición de identidad y diferencia sea la contradicción, que el momento final del "fundamento completo" en la lógica del fundamento absoluto no consista en sustituir simplemente el fundamento (real) por lo fundado, sino en retrotraer a ambos a la relación de fundamentación, que es quien pone, arbitraria o ilegítimamente, algo como fundamento y algo como fundado, y que en la proposición especulativa que aparece ya en la Fenomenología como la verdad del

16 Para Žižek la dialéctica hegeliana descubre ya la lógica de la excepción que según Lacan está a la base de la totalización masculina o, diciéndolo con Žižek, de la ideología; cf. Porque no saben lo que hacen, op. cit., pp. 167-169.

17 Cf., por ejemplo, S. Žižek, El más sublime de los histéricos, trad. A. Bixio, Buenos Aires, Paidós, 2013, pp. 54-61 y 117 ss.

18 Cf., sobre todo, S. Žižek, El espinoso sujeto. El centro ausente de la ontología política, trad. J. Piatigorsky, Buenos Aires, Paidós, 2011, $2^{\text {a }}$ edición aumentada, pp. 85-88.

19 El rechazo por parte de Žižek de la lectura tradicional de Hegel es un rechazo de la interpretación del absoluto como posición sustantiva, pero también, por tanto, como identidad subjetiva que liquida todo resto sustancial; cf. Menos que nada, op. cit., pp. 286-287. 
juicio aristotélico- no sólo el predicado pase a ocupar el lugar del sujeto, sino que, finalmente, sujeto y predicado se hundan a una como cómplices de una misma posición que se desmorona ${ }^{20}$. Tanto la identidad del objeto como la universalidad del concepto como la dualidad del juicio tratan de domar, fijar y ocultar la no coincidencia de la cosa consigo misma. Dicho de otro modo, la contradicción es previa a la identidad y, a la vez, al par de identidad y diferencia. Este carácter originario de la no-coincidencia es lo que expresa la tesis žižekiana de que la dialéctica de Hegel muestra que el universal (totalizador) oculta la verdad del no-todo de la realidad.

Se aprende, por tanto, ya en este tránsito que cualquier posición determinada, esto es, cualquier instancia presupuesta como siendo en-sí, cualquier tesis "sustantiva", eso que se afirma en cada género (totalizador) o en cada juicio (identificador), es en verdad la expresión directa del movimiento ilegítimo, excesivo, por el que la negatividad de la reflexión se pone como principio o subjectum. El momento sustantivo es el mismo ponerse del sujeto, el resultado de que algo se eleva a sub-jectum $^{21}$. Sin embargo, en este momento, aparece todavía como un otro externo (al sujeto), como un extremo de la dualidad propia de la reflexión externa. Explicar esto exige entonces reconocer que esta reflexión oculta, al fijarlo en la exterioridad del dos, el movimiento único del propio ponerse en tanto que acción ilegítimamente totalizadora e identificadora. Ella esconde, en efecto, el origen criminal de la totalidad e identidad de cualquier determinación, de manera que cualquier posición positiva, si se permite la redundancia, se prueba, en este sentido, ideológica.

Ahora bien, en la medida en que se va a pique aquí el sujeto de la reflexión externa, el sujeto como reflexión externa o el principio que contraponía sustancia y sujeto, tesis y antítesis, posición y negación, se hace claro que este contraponer mismo, el movimiento negativo del propio ponerse, ha de ser previo a tal principio, a la reflexión (externa) del sujeto. El golpe por el que caen a un tiempo los dos lados de sus contraposiciones obli-

20 La lógica de las esencialidades de la reflexión (identidad, diferencia y contradicción) y la lógica del fundamento absoluto (fundamento formal, real y completo) explican en claves distintas los momentos de la reflexión de la esencia; cf. G. W. F. Hegel, Ciencia de la lógica. I. La lógica objetiva, op. cit., pp. 459-495 y 499-524. Žižek comenta ambos pasajes en Tarrying with the Negative, op. cit., pp. 130-134 y 136-140. Hegel trata de la proposición especulativa, especialmente, en Fenomenología del Espíritu, op. cit., pp. 125-131. Žižek se ocupa del juicio infinito ("el espíritu es un hueso") en distintos lugares y lo toma como "especulativo" en el sentido de que, expresando la coincidencia de los opuestos, pone a la vista que la contradicción o (no-)identidad especulativa es la verdad del juicio. En este sentido, el juicio infinito produce el mismo resultado que la proposición especulativa fenomenológica, cuyo contenido quiere y no puede desmentir la distancia infinita que separa los dos lados de todo juicio; cf. $E l$ más sublime de los histéricos, op. cit., p. 44; El sublime objeto de la ideología, op. cit., pp. 264-267; Porque no saben lo que hacen, op. cit., pp. 162 y 186. Chaterine Malabou comenta extensamente el descubrimiento del abismo entre los opuestos en la proposición especulativa y localiza en él la apertura del lenguaje hegeliano al por-venir; cf. C. Malabou, L'avenir de Hegel. Plasticité, temporalité, dialectique, París, Vrin, 2015, pp. 231-244.

21 Podemos aquí traducir el par sustancia-sujeto por el lacaniano del gran otro y el sujeto que nace de la identificación, el que es efecto de la cadena significante. Ninguno ocupa la posición originaria, sino que ambos se presuponen. ga, pues, a la reflexión externa a mirar a sus espaldas, finalmente, a desaparecer (como principio) en algo que la precede. Hemos alcanzado ya la reflexión absoluta.

\section{La negatividad abstracta o la destructividad del acontecimiento}

En la reflexión absoluta, en efecto, el movimiento reflexivo se traslada al origen, es decir, a lo que aparecía inicialmente como una posición que es en-sí o por sí misma, como tesis o como sustancia. Pero ahora este origen se auto-retira. $\mathrm{Si}$, tal como dije, la negatividad que ejercía la reflexión externa no era en verdad suya, si se ha descubierto que viene de más atrás de la mediación subjetiva, ella ha de ser entonces, en algún sentido, sustantiva, de la sustancia. Pero la sustancia de la que partimos como origen en-sí o "positivo" ya se nos ha venido abajo, de manera que esta nueva sustancia no podrá consistir finalmente en nada más que en esta pura negatividad. El origen ahora encontrado no es más que negación. Así que la síntesis que ha nacido de la superación, o supresión, de tesis y antítesis, sustancia y sujeto, sólo nos entrega esta nada: en lugar de la sustancia, una brecha (el agujero previo a los opuestos) y en lugar del sujeto, una forma vacía (la negatividad anterior a todo principio). Resulta inevitable traducirlo, con Žižek, al "lacaniano": a la base del gran otro (A) se descubre la "pequeña a" del objeto que lo perfora, el agujero mismo en torno al que se constituye, y a la base del sujeto de las identificaciones simbólicas la barra que lo tacha (\$). La negación era ciertamente -como acababa por saber la reflexión externa- la verdad de la posición, pero se descubre ahora en su verdad como no siendo la negación de algo más (esto es, de alguna posición), como no siendo relativa a tesis alguna, sino como siendo únicamente pura negación o, en los términos de Hegel, absoluta negatividad. Solo así puede no constituirse ella misma como una posición.

Se ha alcanzado aquí una reconciliación en el sentido de que el conflicto entre los opuestos de la reflexión externa ya no es, ha quedado atrás, y lo ha hecho, ciertamente, en la misma medida que el punto de vista de esa reflexión: también ella se ha desvanecido. Pero ambos se han ido a pique en el antagonismo originario, en la pura forma del antagonismo que es esta negatividad absoluta $^{22}$. De manera que un mundo entero se hunde en el parpadeo de una mirada: en un mismo gesto, la realidad (ordenada en torno a un conflicto) y su marco (ese mismo conflicto como punto de vista). Enmudece todo un orden de sentido y se borra, con él, todo el pasado de una historia. Se trata en verdad de "la noche del mundo", tal como vino a expresarse, por ejemplo, en la negatividad abstracta del terror francés ${ }^{23}$. Nos encontramos, por tan-

\footnotetext{
En este punto se hace patente el modo en que Žižek subvierte la comprensión tradicional de la síntesis hegeliana como tercero que nace de la complementación de tesis y antítesis; cf., por ejemplo, Menos que nada, op. cit., pp. 333 ss.

23 Es bien conocida la querencia de Žižek tanto por la metáfora, de la Filosofía real de Jena, de la "negra pupila" que representa el abismo de la subjetividad como por el ejemplo de la necesidad de atravesar la abstracta negatividad antes de negarla en una posición determina-
} 
to, ante el acontecimiento puro, ante el acontecer como absoluta destructividad o, según la distinción de Žižek, ante su primer momento. Es el acontecimiento como punto cero de la historia, como irrupción, injustificada e incomprensible, de lo imprevisible, cuya contingencia es previa a la misma oposición (histórica) entre contingencia y necesidad.

El camino hecho hasta aquí ha sido, en el lenguaje de Lacan, el que lleva del orden simbólico y su sujeto a lo real que los quiebra o, en el lenguaje de Kant, el que iría del ámbito de la experiencia sintetizada por el sujeto soberano - o, como diría Žižek, de la realidad enmarcada- a los extremos que la desbordan y desgarran, los que el propio Kant excluyó o reprimió (de un lado el abismo de la X del sujeto desconocido o el agujero de la libertad para el mal y, del otro, el fantasma de la cosa-en-sí) ${ }^{24}$. Pero al transitarlo con Hegel en la forma de la inversión dialéctica se pone de manifiesto que se trata de un desplazamiento abrupto, cruzado e inevitable: no se ha pasado de una dualidad determinada (o de una determinación conflictiva) a la negación previa al modo en que uno simplemente se eleva a un tercero que viene a unir y distinguir los lados contrapuestos, sino que cada uno de ellos ha llegado a la negatividad originaria convirtiéndose él mismo en su otro, tropezando con su otro como con su propia verdad, como con su negatividad constitutiva.

Como ya anticipé, lo específico y exclusivo de la solución hegeliana para Žižek consiste en explicar el encuentro de los opuestos que articulan nuestra experiencia precisamente así, es decir, sin trascenderlos, sin sobrepasar el ámbito de la inmanencia (finita). El vuelco que tiene lugar en este trayecto se puede ver, en efecto, como el que la cosa o la determinación sustancial experimenta al descubrir al sujeto (en tanto que pura negatividad) como su verdad más interior, o como el que sufre el concepto del sujeto al tropezar con la sustancia (en tanto que pura auto-retirada) como con su núcleo más íntimo, pero se trata en todo caso del (des-)encuentro con el propio límite -con lo que en cada uno de ellos es "más que uno mismo"- como con la propia verdad. Por eso la mediación hegeliana de los opuestos se deja presentar como el salto de una cara a otra en esa banda de Moebius que, por lo demás, sólo posee una única cara ${ }^{25}$. Es, en definitiva, el camino que va del absoluto como sustancia-sujeto al desajuste (de la sustancia, del sujeto y de la sustancia-sujeto) como absoluto.

da que representa el terror jacobino en el capítulo VI de la Fenomenología; cf., por ejemplo, Menos que nada, op. cit., pp. 228 ss.

24 La interpretación de Žižek de la "indocilidad natural del hombre" reconocida por Kant en sus escritos pedagógicos como expresión del abismo del sujeto trascendental o de la negatividad destructiva de la imaginación trascendental en tanto que previa a su función sintetizadora puede leerse en El espinoso sujeto, op. cit., pp. 38-53, esp. 47. Pero la correlación entre el agujero del sujeto trascendental (máximamente explícito a propósito de la apercepción) y la inevitable presencia de las "ficciones" (encarnadas por ejemplo en las Ideas) en la filosofía kantiana es extensamente elaborada ya en Tarrying with the Negative. Kant, Hegel, and the Critique of Ideology, op. cit., pp. 83-124.

25 Para la noción de límite interno, cf. Porque no saben lo que hacen, op. cit., pp. 151-154. A partir de ella se entiende que Žižek recurra a menudo a la "extimidad" lacaniana y a la figura topológica de la banda de Moebius, central también para Lacan, para explicar la inversión hegeliana.

\section{La negación auto-relacionada o la simbolización del acontecimiento}

El recorrido hasta la reflexión absoluta no nos ha conducido a ningún lugar más allá del punto de partida, del sujeto y de la sustancia o de la sustancia-sujeto, porque no hemos hecho más que descubrir el antagonismo puro que se halla a la base de cualquier conflicto. Es justamente en este sentido en el que Žižek afirma que la inversión dialéctica sólo expone un desplazamiento for$\mathrm{mal}^{26}$. La negatividad con la que hemos topado como absoluto desajuste no señala, en efecto, más que la esencial no-coincidencia de cada determinación (o, en términos lacanianos, de cada significante) con su propio lugar ${ }^{27}$. Es únicamente esta estructura contemplada en su pureza, como forma, lo que produce y explica el movimiento que opone los dos lados de un conflicto determinado, es decir, lo que está a la base de cada oposición real o de cada posición determinada, de lo que ve la reflexión externa y de la misma reflexión externa como punto de vista.

Al señalar así que lo encontrado en "el fondo" de cada posición no es la negación que niega y se refiere a un algo otro, sino la negación pura o la forma de la negación, se indica también que este desajuste originario no es un mero vacío, sino una quiebra, que no se trata de la mera nada, sino de la contradicción. Se señala, en definitiva, su carácter auto-reflexivo. Ese agujero o ese abismo es ya siempre plegado, vuelto sobre sí mismo. Que la negación del origen se auto-retira significa, en efecto, que se niega a sí misma, que no puede no volverse contra sí: si nada la precede, ella no puede ejercerse sobre nada más que sobre sí misma. De manera que la negación es ya siempre doble, auto-relacionada $y$, en ese sentido, su nada es "menos que nada". En el origen no encontramos, pues, una simple ausencia, sino una destructividad que, por absoluta, es necesariamente -lo mismo que la pulsión de muerte- autodestructiva ${ }^{28}$.

Pues bien, es esta (auto-)reflexividad lo que explica el poder productivo, creativo en verdad, del abismo de la pura negatividad: que esta pura forma -la forma del antagonismo originario- pueda dar cuenta de todas las contraposiciones que constituyen nuestra experiencia, esto es, la realidad misma. Y es este el sentido en el que el movimiento dialéctico, que, como dice Žižek, se deja exponer tanto en dos, como en tres, en cuatro, o en cinco fases, es siempre reducible a la estructura de los dos tiempos de un contragolpe, a la inversión que, al atender a la puesta en escena o al drama de cada deter-

\footnotetext{
26 Ya en Porque no saben lo que hacen se identifica la dialéctica de Hegel con el ejercicio de captar la pura forma como el vacío que precede al contenido; cf. Porque no saben lo que hacen, op. cit., pp. 209-210 y 216-217. En Tarrying with the Negative se explicita además el carácter formal del desplazamiento que está a la base de cualquier identidad; cf. Tarrying with the Negative, op. cit., pp. 148153. De hecho, Žižek afirma la prioridad del "lado formal" ya en su tesis doctoral; cf. El más sublime de los histéricos, op. cit., pp. $21 \mathrm{ss.}$ 27 Žižek explica la dialéctica hegeliana, relacionándola con la brecha del significante en Lacan, en los términos de esta falta de coincidencia con el lugar propio en The Parallax View, op. cit., pp. 35-37.

28 Para la negación hegeliana como doble negación, cf. Menos que nada, op. cit., pp. 325 ss. Para entender el modo en que la reflexividad nace de la no-coincidencia, tanto en términos hegelianos como lacanianos, cf. The Parallax View, op. cit., pp. 38-40.
} 
minación, se produce por sí misma ${ }^{29}$. Explicar el modo en que esta nada reflexiva se vuelve productiva no es sino transitar el camino ya recorrido en el sentido inverso, atravesarlo en la otra dirección. Tampoco ahora ganaremos un contenido nuevo, sino que únicamente se iluminará la oposición de la reflexión externa, las dualidades reales de tesis y antítesis, género y especie, sujeto y predicado, y por ende sustancia y sujeto, como la expresión de un desplazamiento puramente formal, a saber, del movimiento por el que la pura negatividad (el origen verdadero que sólo es retirándose) se niega $u$ oculta "positivándose" en un conflicto. Comprenderemos simplemente la razón de que el género encuentre su verdad, como antes vimos, en una especie que se reprime, o de que el sujeto lo haga en un predicado que "se excede". En última instancia, el presuponer (la sustancia) de la reflexión externa (como sujeto) se nos dará a ver ahora como no otra cosa que el presuponerse a sí misma de "la cosa" o, si se prefiere, de lo absoluto (como desajuste) que, en tanto que negatividad autorelacionada, tiene necesariamente la forma de un negarse u ocultarse a sí mismo ${ }^{30}$.

Diríase que desde la noche del mundo lo hemos recuperado todo, pero, por otro lado, es claro que, al recorrer así el camino hacia atrás, al pasar, digamos, de la forma al contenido (y no del contenido a la forma), el conflicto recobrado ya no podrá ser el mismo, que el en-sí puesto y presupuesto en el comienzo ya no se sostendrá. En realidad, se ha perdido todo. Ya lo habíamos dicho: el conflicto de partida se ha ido a pique porque se lo contempla ahora desde un lugar que, por haber atravesado la muerte, es verdaderamente otro. La mirada que se abre tras aquel parpadeo del "auto-retirarse del origen" ya no se reconoce, es también otra. La inversión dialéctica, tal como es interpretada por Žižek, sólo consiste, pues, en un cambio en la mirada, pero es, a la vez y por ello mismo, el único cambio radical, el único en el que un mundo entero se desploma para dejar paso a otro.

El trayecto recorrido no es, pues, más que el de un parpadeo que transforma todas las cosas. No extraña entonces que Žižek explique este gesto y este vuelco a partir de la diferencia mínima que produce una "visión de paralaje", del insignificante desplazamiento del punto de mira que transfigura el panorama completo ${ }^{31}$. Ese desplazamiento sólo consiste, efectivamente, en dejar de referir la negación, o el fracaso o la destructividad, a la posición contrapuesta para tomarla en sí misma o en su propio "drama". Pero de esto resulta que ella se invierte absolutamente, que aparece milagrosamente como afirmación o como éxito. En relación a la operación que el propio Hegel practica sobre Kant, sería el simple cambio de perspectiva que permite mirar a la contradicción de las antinomias como a la verdad de las cosas mismas el que habría permitido afirmar por fin el carácter absoluto de la finitud.

\footnotetext{
29 Žižek defiende en varios lugares que el movimiento dialéctico se puede exponer en dos, tres, cuatro o cinco fases; cf. Porque no saben lo que hacen, op. cit., pp. 235 ss. y El espinoso sujeto, op. cit., pp. 88 ss.

30 Para este presuponerse de la cosa, cf. Tarrying with the Negative, op. cit., pp. 146-148.

31 Cf. The Parallax View, op. cit., pp. 17-19.
}

Žižek recurre a menudo a "la mirada" lacaniana para clarificar este punto. No sólo tiene presente la lectura que, en el Seminario XI, hace Lacan de la anamorfosis de Los embajadores de Holbein, en cuya calavera se vuelve visible la propia nada del sujeto que posibilita la inversión de la perspectiva, sino también, especialmente cuando se trata de explicar el tránsito de Kant a Hegel, su comentario del apólogo sobre Zeuxis y Parrhasios ${ }^{32}$. La interpretación de Lacan, efectivamente, aun cuando su única referencia filosófica explícita sea Platón, se deja conectar fácilmente con la liquidación hegeliana de la cosa-en-sí como "giro anamórfico" en el que la trascendencia de lo en-sí se descubre como el fantasma que la ficción real, o la realidad en tanto que ficción que enmascara el vacío originario, pone o proyecta para constituirse.

Se entiende ahora, pues, que el momento destructivo del Acontecimiento, el golpe de la inversión dialéctica, constituya en sí mismo la fuente de un nuevo orden de sentido, que el desmoronamiento del todo del pasado que acontece en el punto cero de la historia suponga a la vez el surgimiento de un nuevo tiempo y/o una nueva historia, esto es, de un mundo nuevo. La pura negatividad abstracta del irrumpir del acontecimiento entraña ya, como contragolpe, la emergencia de una palabra y una acción nuevas. Podríamos decir -al menos provisionalmente- que acontecen una palabra y una acción primeras, originarias. En términos de Žižek, se produce una nueva simbolización de la realidad ${ }^{33}$. Que el conflicto de partida se haya desvanecido, que ya no sea (el nuestro), sólo es posible porque el lugar de nuestra mirada ya se ha desplazado, porque ya estamos en otro sitio. Y estamos en otro, en un presente nuevo, porque ya nos hemos dado otro pasado, esto es, porque la historia ya se ha reescrito $^{34}$. En el primer momento del acontecimiento ha sucedido lo imposible, es decir, lo que era imprevisible, lo que no se dejaba explicar por la historia y el mundo precedentes, y por eso ahora la quiebra de su presente ha de darse sus propios presupuestos. Dárselos y fundar un sujeto y un mundo nuevos es lo mismo ${ }^{35}$.

32 Cf. J. Lacan, Le semináire. Libre XI, ed. J. A. Miller, París, Editions du Seuil, 1973, esp. pp. 98-103 y 122-129.

33 Es bien sabido que no se trata en todo caso de dos gestos: la afirmación de un concepto es ya siempre una acción. No hay, por tanto, un punto de vista que pueda ser verdaderamente pasivo. Y, por otro lado, como Žižek mismo explica muy bien, a partir del caso del alma bella, toda acción es en primera instancia una acción simbolizadora, representadora o, si se quiere, teórica; cf. El sublime objeto de la ideología, op. cit., p. 274.

34 Para el acontecimiento como el Acto que en un mismo gesto borra una historia y escribe otra al darse sus propios presupuestos, $\mathrm{cf}$. Menos que nada, op. cit., pp. 230-244 y Acontecimiento, trad. R. Vicedo, Madrid, Sexto Piso, 2014, pp. 100-104. A este punto cero de la historia se refiere Žižek a menudo como al momento a-histórico de la historia; cf., por ejemplo, El más sublime de los histéricos, op. cit., p. 89. En El sublime objeto de la ideología se refiere también a él como al vacío "entre las dos muertes" del que habla Lacan; cf. El sublime objeto de la ideología, op. cit., p. 181.

35 Žižek explica en distintos lugares cómo la inversión dialéctica, bien entendida, obliga entonces a reinterpretar la teleología hegeliana, y la astucia de la razón, como retroactiva; cf., por ejemplo, El más sublime de los histéricos, op. cit., pp. 99 ss. y Menos que nada, op. cit., pp. 230 ss. Para la prioridad ontológica de la contingencia y la "anamorfosis temporal" que hace aparecer lo contingente como necesario, cf., por ejemplo, Tarrying with the Negative, op. cit., p. 156. Para la cuestión de lo virtual y lo imprevisible, cf. Menos que nada, 
Se pone de manifiesto así que a la base de cada nueva determinación de la Ciencia de la Lógica, y de cada nueva figura de la Fenomenología, está siempre, y siempre oculto, el paso por el terror de la muerte, por la noche del mundo, por la violencia y la contingencia de la pura y abstracta negatividad ${ }^{36}$. Según la interpretación de Žižek Hegel sabe que, del mismo modo que la necesidad histórica tiene a su base la contingencia, la libertad como autonomía (subjetiva) descansa sobre una acción huérfana, previa a la constitución misma del sujeto, y sabe también que la significación del lenguaje arranca de una palabra previa al sentido ${ }^{37}$. Por eso su trabajo dialéctico enseña cómo cada mundo o cada universal lleva dentro de sí la muerte, la falta de sentido, como su destino, y por eso en la cúspide -y a la vez en el margen- de cada orden, de cada configuración, se puede rastrear el momento de arbitrariedad sobre el que se sostiene ${ }^{38}$. La dialéctica es un drama trágico. Se comprende, pues, que, para Žižek, Lacan, sin saberlo, explique mejor que nadie el contragolpe dialéctico al descubrir en el origen del sujeto identificado y del orden simbólico la imposición violenta de un significante mudo que, como significante maestro, fija y ata, al modo del point de capiton, los significantes "flotantes" en la cadena significante, es decir, que hace posible, en definitiva, el discurrir del lenguaje y del tiempo (del deseo). Este es ciertamente el mismo gesto por el que la cosa misma, la absoluta negatividad, se presupone a sí misma al ponerse como sujeto y al presuponer la sustancia, al "positivar" su desajuste en la contraposición de un sujeto y una sustancia ${ }^{39}$.

Ambos, Hegel y Lacan, en virtud de la reflexividad de la negación o de la pulsión originarias, dejan también ver, según esto, que la nueva simbolización, el lenguaje y la historia nuevos, ocultan o reprimen la misma violencia o negatividad de la que nacen. El mundo que se abre en el acontecimiento nace para negar su propio origen: es el modo en el que el origen se auto-retira o la negatividad absoluta se vuelve contra sí. Cada mundo es el contragolpe que da sentido al sinsentido (del puro significante) y enmascara la arbitrariedad del punto cero de la historia en el discurrir continuo de la línea del tiempo. Cada mundo es, en este sentido, ficticio o

pp. 237-243. En Acontecimiento aparece este mismo tema bajo el prisma del "milagro"; cf. Acontecimiento, op. cit., p. 150.

36 En este sentido insiste también Žižek en la necesidad de errar, en que la primera elección ha de ser siempre "la mala", por una necesidad arraigada en la realidad misma. De nuevo, frente a Kant, el error se ilumina como siendo "verdadero", perteneciente a la estructura misma de lo real, y no como meramente "subjetivo", fundado en las limitaciones del sujeto.

37 Cf. G. W. F. Hegel, Enciclopedia de las ciencias filosóficas, op. cit., $\S \S 408-410$. El descubrimiento de un "momento zombi" en la reduplicación de la naturaleza de la que nace el espíritu y de la locura a la base de la subjetividad lingüística es crucial para Žižek. En Menos que nada se refiere a este tránsito a través del comentario del pasaje acerca de la noción de hábito pre-lingüístico de El porvenir de Hegel, de Catherine Malabou; cf. Menos que nada, op. cit., pp. 378 ss.

38 El ejemplo paradigmático de esto es para Žižek el monarca hegeliano, que sólo pone "el punto sobre la i", en la cúspide del Estado moderno de la Filosofia del Derecho; cf. Menos que nada, op. cit., pp. 463 ss.

39 Para la auto-presuposición como expresión de la auto-reflexividad, cf., por ejemplo, Tarrying with the Negative, op. cit., p. 147 y The Parallax View, op. cit., p. 39. mentiroso constitutivamente. La realidad, como descubrió Kant al decir que está trascendentalmente enmarcada, expresa siempre una perspectiva, la mirada del sujeto. Pero ahora sabemos por qué: nace de un punto de vista porque sólo así -mirándose, reflexionándose o volviéndose sujeto- puede ocultar la brecha de su origen, su propia brecha o su ser no-todo ${ }^{40}$. Por eso la realidad es ella misma siempre distorsionada y por eso el cambio de perspectiva la transforma absolutamente ${ }^{41}$. Al mostrar esto, la dialéctica hegeliana, antes que el psicoanálisis lacaniano, descubre para Žižek el carácter constitutivamente ideológico de nuestra realidad ${ }^{42}$. Lenguaje e historia nacen ambos de la pérdida o de la negación originaria y no son más que su auto-reflexión o autonegación, la pérdida de la pérdida o la negación de la negación. Por eso sólo contradiciéndose dice el lenguaje su verdad y sólo deconstruyéndose dice la historia la suya. Lacan rastrea la contradicción en el discurso del paciente y Hegel deja ver como cada figura histórica y cada posición teórica o lingüística se desmorona por sí misma: deja siempre que se vaya destejiendo mientras se teje. En esto consiste el ejercicio dialéctico.

\section{El tiempo no es}

Sólo nos queda ahora tirar el andamio del que nos hemos valido para explicar la inversión dialéctica como acontecimiento. Para ello hace falta en primer lugar reparar en que, en verdad, no ha habido nunca una primera palabra ni una primera acción, en que esta posición -tomada como un origen que es positivamente o en-sí- es siempre puesta por un mundo y una historia que la preceden, y que, en consecuencia, se constituye como una ficción o mito. Si recordamos que la tesis como punto de partida del movimiento dialéctico, la sustancia como siendo en-sí (y no como movimiento

40 Lacan da cuenta también, como Hegel, del descubrimiento kantiano: en sus términos, el marco de la realidad es siempre la fantasía del gran otro, que nos dice cómo desear.

41 El cambio de perspectiva acontece en la inversión dialéctica, que es el movimiento de la realidad misma, porque la realidad es siempre desde una perspectiva, porque la mirada pertenece al cuadro, o, dicho de otro modo, porque la sustancia es ya siempre subjetiva; cf., por ejemplo, Porque no saben lo que hacen, op. cit., p. 147. Pero esto no significa que no haya nada más que interpretaciones -como piensa cierta posmodernidad-, sino que el núcleo (ciertamente duro) de la realidad es un antagonismo originario, aunque formal, que exige el conflicto y la transformación de las miradas. El ejemplo más empleado por Žižek para ilustrar el carácter rigurosamente real de la distorsión de la mirada es el caso, recogido por Lévi-Strauss, de las dos descripciones incompatibles de una misma aldea por parte de los miembros de la tribu de los Winnebago; cf. Contragolpe absoluto, op. cit., pp. 110-111.

42 Empleo aquí el término "ideología" en el sentido que le imprime Žižek en general, es decir, para referirse a cualquier posición que es cómplice de y sanciona la ilusión de que la realidad es "toda". Por supuesto esta noción presupone la marxista y parte de ella, pero es redeterminada por Žižek al ser releída desde su interpretación cruzada de Hegel y Lacan. Esto justifica el anacronismo en el que aquí intencionadamente incurro. Sobre el modo en que Žižek reelabora la noción de ideología consumando una "desviación" respecto del marxismo clásico iniciada ya por Althusser puede leerse S. CastroGómez, Revoluciones sin sujeto. Slavoj Žižek y la crítica del historicismo postmoderno, Madrid, Akal, 2018, pp. 75-92. 
de auto-retirada), ya se nos ha desmoronado, vemos que cuando partimos del significante puro como representante de una esfera pre-simbólica subsistente de suyo para poder después explicar "por pasos" el vuelco dialéctico, empleamos el lenguaje del mito y no el de la dialéctica. Hacemos entonces lo que Lacan cuando, en ocasiones, especialmente en su primera etapa, parecía postular un Real "sin falta", cerrado sobre sí mismo, autónomo y previo al orden simbólico, o lo que, aún en Las edades del mundo, hacía Schelling cuando describía un fundamento y un tiempo previos a la existencia, esto es, al lenguaje y a la historia.

Al afirmar que la simbolización de un orden es siempre una resimbolización, que la escritura de la historia es siempre una reescritura, Žižek deja muy claro, a mi parecer, que su camino no es el schellingiano, sino el hegeliano, y que su Real no es ese "primer Real" de Lacan, sino más bien el que Lacan pensó en su última época, el que sólo se realiza en sus efectos dentro del orden simbólico ${ }^{43}$. Es lo real del mismo Lacan que, asumiendo que el trauma, como narración, se origina en el trabajo clínico mismo, que es siempre aprescoup, ofrece una verdadera alternativa al "psicoanálisis del yo", a esa lectura de Freud que permanece atada a un pasado pre-simbólico a recuperar y simbolizar en la terapia. El trabajo de Žižek sobre Hegel se deja leer, en este sentido, como la repetición del que sobre Freud hizo Lacan: del mismo modo que éste liberaba a aquél de un inconsciente sustancial, Žižek libera a Hegel de las interpretaciones que lo amarran a un absoluto sustantivo.

Ya señalé esto mismo cuando constaté más arriba que la inversión dialéctica, tal como es interpretada por Žižek, no nos lleva desde el conflicto de sustancia y sujeto a un tercero externo a ellos que venga a unificarlos, sino que más bien se limita a describir la torsión que la propia sustancia y el propio sujeto sufren al ser atravesados por una mirada que renuncia al suelo firme de una perspectiva externa, y que lo único que acontece en esa torsión es que cada uno de ellos se va a pique al tropezar con su otro ${ }^{44}$. Pues bien, hemos de reparar ahora en que esto ocurre porque cada uno de ellos es ya siempre precedido por su otro: la sustancia precede

43 En su libro sobre Žižek, Adrian Johnston (Žižek's Ontology. A Transcendental Materialist Theory of Subjectivity, Evanston, III, Northwestern University Press, 2008) distingue ya estas dos comprensiones de lo Real en Lacan, pero es John Carew quien ha fijado la diferencia como la que habría entre un Real ${ }_{1}$ y un Real ${ }_{2}$. Carew, aunque tiene en cuenta los lugares donde Žižek niega un Real "sin falta", dada la exposición que luego hace de su pensamiento, parece conceder que también en Žižek se mantiene una cierta oscilación entre los dos Reales; cf. J. Carew, Ontological Catastrophe: Žižek and the Paradoxical Metaphysics of German Idealism, Ann Arbor, Open Humanities Press, 2014, pp. 28-34. A mi parecer, en cambio, es claro que Žižek opta por el segundo Real. En Contragolpe absoluto, por ejemplo, es muy explícito respecto a esto: nada precede a la caída, la pérdida es siempre pérdida de la pérdida; cf. Contragolpe absoluto, op. cit., pp. 145 ss. y 159.

44 También al subrayar más arriba que la palabra o el acto primero sólo es ocultándose, he indicado ya que no tiene en verdad existencia (positiva) alguna al margen de sus efectos, independientemente del orden simbólico al que sustenta, en la medida en que, precisamente, se autoexcluye o reprime. El origen, en definitiva, no es una realidad positiva, sino solamente el acto mismo de auto-retirada (o autorepresión) de la negatividad absoluta. al sujeto y el sujeto a la sustancia. Sólo por esto logra Hegel transgredir la prohibición kantiana de vincularlos, esto es, hacer metafísica como Schelling y a diferencia de Fichte y, a la vez, sin embargo, ser también más fiel a Kant -a la liquidación de la trascendencia inscrita en el propio giro trascendental- de lo que lo fue él mismo y, por supuesto, Schelling ${ }^{45}$. Dicho brevemente: la razón de que, para Žižek, Hegel ocupe un lugar señalado, excepcional, incluso dentro del Idealismo alemán, reside en que es él el único que ha ganado una metafísica verdaderamente trascendental, una metafísica que realiza verdaderamente la afirmación de la finitud que implica el planteamiento kantiano. Esto fue posible porque supo ver que los opuestos se vinculan, coinciden incluso, en un desajuste que es lo más propio de cada uno y que es lo único absoluto. Esta falta de coincidencia -y consistencia- interna es lo que hace que cada uno encuentre en su centro a lo otro como algo que lo precede, que surge de la oscuridad que queda a sus espaldas y lo sorprende, que expresa el punto ciego de su mirada y que, por tanto, acontece.

Así es cómo la relación hegeliana entre los opuestos subvierte como ninguna otra el orden del tiempo e impide, a mi parecer, seguir tratando de comprender la inversión dialéctica como el paso de un primer momento a un segundo momento. Por supuesto, tanto Hegel como Žižek utilizan el "lenguaje de la representación" para explicarla, hablan en los términos de un antes y un después, y recurren incluso a la imagen del origen, al lenguaje del mito. Hegel describe la sustancia inmediata, una y toda, de la Sittlichkeit griega y Žižek reconstruye con total fruición el fundamento roto de Schelling o el vórtice de la pulsión pre-simbólica a propósito del Don Juan kierkegaardiano, pero ambos hacen el camino de vuelta que deja ver lo primero como segundo, el origen presupuesto como puesto por lo originado. Éste es el modo en que fuerzan a la línea del tiempo del relato a plegarse sobre sí como un círculo que, sin embargo, se sabe roto, que no puede no abrirse siempre de nuevo en la línea ${ }^{46}$.

Por este motivo me resisto, por un lado, a reducir el Hegel de Žižek a un autor más en el desarrollo de la Grundlogik del Idealismo alemán (que sería lo realmente importante para él) y, por otro, a insistir -como hacen, por ejemplo, John Carew y Adrian Johnstonen preguntar a Žižek por "la condición suficiente" que explicaría el paso de la sustancia rota a la posición del sujeto $^{47}$. Creo ciertamente que, desde la perspectiva

45 Que la respuesta de Hegel a Kant es la que nace de esta doble operación se infiere, pienso, de las explicaciones que Žižek ofrece del tránsito de Kant a Hegel en todas sus obras sobre Hegel.

46 Para la dialéctica de eternidad y tiempo, mirada desde el acontecimiento y como desenmascaramiento de que "el tiempo no es", cf. S. Žižek, El frágil absoluto o ¿Por qué merece la pena luchar por el legado cristiano?, trad. A. Gimeno, Valencia, Pre-Textos, 2002, pp. 121-126.

47 Carew considera que no es claro que esté justificada la preferencia de Žižek, a menudo expresada por él mismo, por Hegel frente a Schelling (cf. Ontological Catastrophe, op. cit., pp. 48-49). Sostiene que, precisamente para “cerrar" la explicación del tránsito de la sustancia al sujeto, Žižek ha de recurrir necesariamente a Schelling, pues en él encuentra claves al respecto que no están presentes en Hegel (cf. Ontological Catastrophe, op. cit., pp. 136 y 143). La pregunta por la causa suficiente del tránsito de la sustancia al sujeto hegelianos se la 
que ofrece la interpretación žižekiana de Hegel, o bien se ha de rechazar esa pregunta como se rechazan los intentos de aprehender a través de causas suficientes aquello que simplemente "acontece" (el círculo explota), o bien se ha de replicar que a la sustancia rota la precede ya el sujeto (la línea se dobla) ${ }^{48}$.

Pero pienso además que este tiempo contradictorio es, en efecto, el de Hegel. Sólo desde su paradoja se entiende la identidad y la diferencia que él mismo establece entre el pasado y el presente. Ya en el EScrito sobre la diferencia dice Hegel que el presente comunica con el pasado, incluso coincide con él, solamente en la medida en que comparten el antagonismo, el conflicto, en torno al cual se estructura cada época de un modo diferente ${ }^{49}$. Es decir, el pasado coincide con el presente precisamente en la medida en que el presente, el tiempo (en su existencia), esta roto (entre él y su pasado). Presente y pasado convergen, en definitiva, en virtud del desajuste (formal) que constituye cada presente, y se distinguen en virtud de la determinación positiva o del contenido con el que cada presente oculta, simboliza, o positiviza el conflicto originario que él -la única realidad del tiempo- es. Sólo por eso la filosofía de Hegel es siempre, incluso cuando se constituye como reconstrucción histórica, aprehensión del presente ${ }^{50}$. A esta luz, y no a la del $\S 82$ de Ser y tiempo, es a la que, a mi parecer, se ha de leer el final de la Fenomenología del Espíritu, la relación que allí se establece entre la eternidad del espíritu y la existencia del mismo como tiempo: es la (no-)coincidencia del círculo y la línea lo que aquí se afirma, esto es, el movimiento del tiempo como la conjunción imposible del romperse del círculo en una línea y de la torsión sobre sí de la línea en el círculo $^{51}$. Es por haber rescatado este tiempo de Hegel por lo que Žižek descubre la apertura de la dialéctica, no al modo de Adorno, sumando a la dialéctica "afirmativa" un plus de negatividad, sino reconociendo la

plantea a Žižek no sólo Carew, sino también Johnston; cf. J. Carew, Ontological Catastrophe, op. cit., pp. 135-136 y A. Johnston, Žižek's Ontology, op. cit., pp. 162-167, 202 y 223.

48 Johnston localiza acertadamente la clave de la inversión dialéctica al retrotraerla al tiempo, pero no logra, a mi parecer, hacerse cargo de la radicalidad con la que Hegel y Žižek lo subvierten: se aproxima de nuevo a su contradicción en el lenguaje de la representación que la analiza en dos momentos para luego yuxtaponerlos y poder proporcionarle así un contorno final, un "aspecto", a lo que no lo puede tener (cf. A. Johnston, Žižek's Ontology, op. cit., pp. 235-268). Es, a mi parecer, este pliegue del tiempo el que explica el bucle comentado más arriba entre la mirada y la cosa, la sustancia y el sujeto: la realidad toda se va a pique en un parpadeo y nace otra por la nueva mirada, pero la mirada se transforma también porque el hundimiento del mundo ya ha acontecido. Todo este proceso está condensado en la idea de Hegel de que "la causalidad se presupone a sí misma"; $c f$. G. W. F. Hegel, Ciencia de la lógica. I. La lógica objetiva, op. cit., p. 632 .

49 G. W. F. Hegel, Diferencia entre el sistema de filosofia de Fichte y el de Schelling, trad. J. A. Rodríguez Tous, Madrid, Alianza, 1989, p. 10.

50 G. W. F. Hegel, Principios de la filosofia del derecho, trad. J. L. Vermal, Barcelona, Edhasa, 1999, p. 61.

51 Cf. G. W. F. Hegel, Fenomenología del Espíritu, op. cit., pp. 909-911 y las reflexiones al respecto de J. Derrida, "Ousia y Gramme. Nota sobre una nota de Sein und Zeit”, en Márgenes de la filosofía, trad. C. González María, Madrid, Cátedra, 1989, pp. 63-102, así como las de C. Malabou, L'avenir de Hegel, Paris, Vrin, 2015, pp. 175-179. absoluta negatividad en el corazón mismo de la inversión hegeliana ${ }^{52}$.

\section{La dialéctica como crítica de la ideología}

El saber absoluto de Hegel es el que conoce el tiempo como este tiempo de la inversión dialéctica o el que sabe que el presente (la identidad, la universalidad, cualquier posición) está roto y replegado. No sólo sabe de su quiebra, sino también de la necesidad de que-ilegítima o fraudulentamente- se suture en la continuidad de la historia, de que exprese y suprima ese gesto que, en general, o en términos de la lógica, consiste en que lo que no tiene identidad se ponga como idéntico, lo que carece de universalidad se ponga como universal y, en definitiva, lo puramente negativo se autoafirme o se (presu)ponga como sujeto/ sustancia.

El saber absoluto sabe que no podemos no elevarnos -ilegítima o ideológicamente- a un orden de sentido y al telos de una historia o, dicho de otro modo, que es inevitable que mintamos y pequemos cada vez que juzgamos y actuamos ${ }^{53}$. Y sabe también que cada orden oculta una realidad no-toda y cada historia se sostiene sobre una contingencia, que, en definitiva, el marco de la realidad es una ficción (en términos lacanianos, que el orden simbólico se sostiene simplemente sobre una fantasía), y que, en consecuencia, el destino del orden, al igual que el de cada acción y cada juicio, sólo puede ser trágico.

En mi opinión, esto pone de manifiesto que en la filosofía de Hegel la contradicción o el trauma de lo Real no sólo se trasluce como aquello que finalmente permanece reprimido, sino que es enfrentado y sabido, o, dicho más hegelianamente, que no es meramente en-sí, sino también para sí. El propio Žižek, por decirlo así, reconoce y expone el pensamiento de Hegel como poniendo él mismo en obra el trabajo del psicoanálisis (lacaniano). Por esta razón, a mi parecer, el Hegel de Žižek no puede ser, en contra de lo que sugieren algunos comentaristas, el simple resultado de una lectura psicoanalítica, operada desde fuera, del texto hegeliano, la mera (re)construcción de un "no-dicho" oculto en su texto ${ }^{54}$. Esta consideración apuntala, más o menos abiertamente, la idea de que la "verdadera" posición de Hegel -o, al menos, la sabida y querida por él- es la que transmite la lectura tradicional, es decir, la que entiende la dia-

52 En Menos que nada Žižek explica sucintamente la razón por la que rechaza la operación que Adorno lleva a cabo sobre Hegel; cf. Menos que nada, op. cit., pp. 288 ss.

53 Žižek comenta la dialéctica de la conciencia juzgadora y actuante de la Fenomenología en El más sublime de los histéricos, op. cit., pp. 93 ss.

54 Carew entiende que, en la filosofía de Hegel, lo mismo que en la de los demás idealistas alemanes, es posible encontrar lo Real lacaniano-žižekiano, pero que ella misma acaba por rehuirlo o reprimirlo: es sólo la labor "terapéutica" de Žižek la que lo trae a primer plano. Este diagnóstico es lo que explica que, finalmente, Carew equipare el significado real de Hegel para Žižek al que tienen los demás idealistas, en tanto que también interpretados o psicoanalizados por él; cf. J. Carew, Ontological Catastrophe, pp. 37-42. 
léctica como el cumplimiento de un telos originario que finalmente acaba por clausurar la historia. Pero precisamente porque la contradicción es para-sí en Hegel, o, en última instancia, porque, como ya he razonado, su saber conoce la contradicción del tiempo, me resisto también a aceptar que esta lectura, todavía hoy habitual, sea más fiel a su pensamiento que la de Žižek, esto es, que la que interpreta la dialéctica como acontecimiento.

Ahora bien, incluso suscribiendo la interpretación žižekiana, parece posible volverse también contra su Hegel, contra el saber absoluto reinterpretado ya como el saber del carácter constitutivamente ideológico de nuestra experiencia, por no ofrecernos en todo caso una posición desde la que criticar y combatir la ideología. Es decir, parece posible preguntarse de todos modos si este saber, finalmente, no nos deja enfrentados al dilema entre retirarse de la acción, para evitar mentir y pecar, o prolongar cínicamente, cómplices de la ideología, el teatro de la historia. Y, si así fuera, ¿no habríamos entonces de reconocer que también este nuevo Hegel nos colocaría en un final de la historia, y, ciertamente, en uno más agrio que aquel que tradicionalmente se le ha atribuido ${ }^{55}$ ?

Pienso que para Žižek todo se juega aquí en la diferencia entre dos modos de decir (y de saber) este carácter puesto y presupuesto, ideológico, de la realidad. Valiéndonos de las fórmulas lacanianas de la sexuación, a las que él mismo recurre a menudo, habría que señalar que hay una diferencia entre decir "todo marco es una ficción" y decir "no hay marco alguno que no sea una ficción". La primera descripción nos destina efectivamente al dilema entre la absoluta pasividad o la entrega (más o menos cínica) a la ideología, pero la segunda nos recuerda el vacío que quiebra cada ficción y que sin embargo la sostiene por detrás como su forma pura o como el desplazamiento en que consiste el "ficcionar". Mirar así el carácter ideológico o ficticio de la realidad lo cambia todo: sustituye la perspectiva desde la que nos vemos presos y esclavos de la fantasía por aquella desde la que nos sabemos capaces de "atravesarla" 56 . Al describir la realidad de este modo dialéctico, o, digamos, femenino, no se suprime la lógica (masculina) de la excepción y la totalización, sino que más bien, por decirlo hegelianamente, se la "aprehende conceptualmente": se comprende la procedencia de cada identidad y de cada totalidad, se las atraviesa con la mirada para descubrir su drama, lo que en ellas ha acontecido. Y cuando se puede ver lo real del acontecimiento que ya ha sido, no se puede entonces más que expresarlo, simbolizarlo o consu-

\footnotetext{
Esta reserva expresa el punto de vista que se pregunta si la posición žižekiana logra realmente constituir una alternativa al "relativismo" posmoderno que combate.

56 Žižek expone las fórmulas lacanianas de la sexuación con mucha claridad en, entre otros lugares, Tarrying with the Negative, op. cit., pp. 53 ss. En esa misma obra, más adelante, se utilizan para mostrar que es lo Real lo que explica que haya una diferencia entre "todo es puesto" y "no hay algo que no sea puesto": es sólo por lo Real (ningún "algo" positivo) por lo que no es cierto que "todo" sea puesto, por lo que la segunda fórmula es, pues, "más verdadera" (cf. Ibidem, pp. 128-129).
}

marlo. Con este cambio mínimo de perspectiva (el que expresa la diferencia entre decir "todo relato es ideológico" y decir "no hay relato alguno que no sea ideológico") no se conjura para siempre la totalización, pero se la aprehende desde el universal concreto, esto es, como la expresión de un desplazamiento formal e irreductible que está destinado al fracaso ${ }^{57}$. Se mira el todo desde la transformación que lo corroe o desde lo absoluto como absoluta negatividad transformadora. Así visto, ya se ha subvertido y ya no es. Pues bien, la dialéctica hegeliana es para Žižek femenina, no dice nunca que toda posición cae, sino que no hay ninguna -ninguna figura de la conciencia ni ninguna determinación de la lógica-que no caiga. Por este motivo es, pues, en sí misma, y ya antes de que se acuñase el término, crítica de la ideología.

Ahora bien, este mirar no se ha de confundir con un pasivo contemplar sub specie aeternitatis el fracaso de las sucesivos ensayos por encarnar lo universal, el avanzar (hacia ninguna parte) del universal concreto. No hay tal en Žižek. Su opción es, clara y rotundamente, la acción, el universalizar y, por tanto, el mentir y el pecar que conllevan. Podríamos objetar de nuevo, como el vallet de chambre, que se trata, en fin, de una elección forzada, pero, a mi juicio, esta afirmación de la acción no expresa solamente el mero reconocimiento de su inevitabilidad. Efectivamente, no queda más remedio que actuar y, por tanto, elevarse ilegítimamente a la universalidad, pero cuando se actúa, se peca y se miente desde la perspectiva dialéctica se sabe que el pecado, la falta y la mentira pertenecen a la realidad misma y que, en esta medida, se está respondiendo a ella adecuadamente, haciendo justicia a su verdadera constitución. Se "acierta" entonces al actuar, porque el mentir y el pecar se reconocen en su necesidad y se afirman en su verdad. Y en esta medida, el actuar dialéctico, histérico, hace de la mentira verdad y del pecado justicia. Conducirse o mirar dialécticamente coincide, pues, con ese gesto -al que me refería más arriba- que, al comprender la realidad desde el universal concreto, registra y consuma el acontecimiento que ella esconde, de modo que libera y repite la revolución que encierra. Precisamente de esta forma se relaciona Žižek con la historia de la filosofía: vuelve al pasado para redimir las expectativas allí fracasadas, para repetir el antagonismo que allí silenció la historia escrita ${ }^{58}$. En este ejercicio filosófico su encuentro con Hegel resulta excepcional, porque es el encuentro con el pensamiento que por primera vez miró así a la historia, que ya supo reconocer en ella el acontecer del presente. Por eso el pensamiento de Hegel acontece para Žižek de una forma señalada: es, en la historia de la filosofía, el momento del acontecimiento ${ }^{59}$.

\footnotetext{
Para la comprensión žižekiana de la universalidad concreta, cf. Menos que nada, op. cit., pp. 399 ss.

58 Su reconocimiento de Benjamin es explícito ya desde su tesis doctoral; cf. El más sublime de los histéricos, op. cit., pp. 187-202; El sublime objeto de la ideología, op. cit., pp.182 ss.

59 La investigación conducente a este artículo ha sido financiada por la Agencia Estatal de Investigación del Ministerio de Ciencia e Innovación del Gobierno de España (Proyecto de Investigación: "La teleología en la obra lógica de Hegel”, PGC2018-093363-B-I00), en parte con fondos Feder de la Unión Europea.
} 


\section{Bibliografía}

Adorno, Th. W., "La sustancia experiencial", en Tres estudios sobre Hegel, trad. V. Sánchez de Zavala, Madrid, Taurus, 1974.

Carew, J., Ontological Catastrophe: Žižek and the Paradoxical Metaphysics of German Idealism, Ann Arbor, Open Humanities Press, 2014.

Castro-Gómez, S., Revoluciones sin sujeto. Slavoj Žižek y la crítica del historicismo postmoderno, Madrid, Akal, 2018.

Derrida, J., "Ousia y Gramme. Nota sobre una nota de Sein und Zeit”, en Márgenes de la filosofía, trad. C. González María, Madrid, Cátedra, 1989.

Hegel, G. W. F., Diferencia entre el sistema de filosofía de Fichte y el de Schelling, trad. J. A. Rodríguez Tous, Madrid, Alianza, 1989.

-, Fenomenología del Espíritu, trad. A. Gómez Ramos, Madrid, Abada, 2010.

-, Ciencia de la lógica. I. La lógica objetiva, trad. F. Duque, Madrid, Abada, 2011.

-, Principios de la filosofia del derecho, trad. J. L. Vermal, Barcelona, Edhasa, 1999.

-, Enciclopedia de las ciencias filosóficas en compendio, trad. R. Valls, Madrid, Alianza, 1997.

Johnston, A., Žižek's Ontology. A Transcendental Materialist Theory of Subjectivity, Evanston, III, Northwestern University Press, 2008.

Lacan, J., Le semináire. Libre XI, ed. J. A. Miller, París, Editions du Seuil, 1973.

Malabou, C., L'avenir de Hegel. Plasticité, temporalité, dialectique, París, Vrin, 2015.

Žižek, S., El sublime objeto de la ideología, trad. I. Vericat, México, Siglo XXI, 1992.

-, Tarrying with the Negative. Kant, Hegel, and the Critique of Ideology, Durham, Duke University Press, 1993.

-, El frágil absoluto o ¿Por qué merece la pena luchar por el legado cristiano?, trad. A. Gimeno, Valencia, Pre-Textos, 2002.

-, Porque no saben lo que hacen. El goce como un factor político, trad. J. Piatigorsky, Buenos Aires, Paidós, 2006, pp. $215-218$.

-, The Parallax View, Cambridge (Mass.)/London, The MIT Press, 2009.

-, El espinoso sujeto. El centro ausente de la ontología política, trad. J. Piatigorsky, Buenos Aires, Paidós, 2011, $2^{\mathrm{a}}$ edición aumentada.

-, El resto indivisible, trad. A. Bello, Buenos Aires, 2013.

-, El más sublime de los histéricos, trad. A. Bixio, Buenos Aires, Paidós, 2013.

-, Acontecimiento, trad. R. Vicedo, Madrid, Sexto Piso, 2014, pp. 100-104.

-, Menos que nada. Hegel y la sombra del materialismo dialéctico, trad. A. J. Antón, Madrid, Akal, 2015.

-, Contragolpe absoluto. Para una refundación del materialismo dialéctico, trad. A. J. Antón, Madrid, Akal, 2016. 